\title{
The Teaching Model Research of Class-Selection System for Zhejiang High School
}

\author{
Hailiang Zhang* \\ Department of Mathematics \\ Zhejiang Ocean University \\ Zhoushan 316000, China \\ hlzhang88wy@163.com
}

\author{
Binbin Wang \\ Department of Mathematics \\ Zhejiang Ocean University \\ Zhoushan 316000, China \\ 1497658681@qq.com
}

\author{
Huanhuan Xiong \\ Department of Mathematics \\ Zhejiang Ocean University \\ Zhoushan 316000, China \\ xionghuanhuan1995@163.com
}

\begin{abstract}
Since the new college entrance examination system will be implemented in Zhejiang province of China in 2017, the class-selection system teaching will become an inevitable choice for senior high school education under the new situation. In this paper, we summarize the characteristics of class-selection system teaching and put forward three kinds of research methods for class-selection system teaching mode. Based on this, the necessary conditions are obtained to satisfy the class-selection system teaching. The results of this study can promote the scientific development of class-selection system teaching in senior high school.
\end{abstract}

Keywords-College entrance examination, Class-selection system, Senior high school, Teaching mode

\section{INTRODUCTION}

Starting in 2017, China will implement the comprehensive reform of college entrance examination in the country. It means that three subjects of Chinese language and literature, mathematics and foreign languages will become national exams. Meanwhile students should choose 3 examinations from politics, history, geography, physics, chemistry, biology optionally. Based on this reform, mobile learning system is likely to be implemented in Chinese high schools.

Chinese domestic educators' understanding of the new teaching system is behind of the process of the reform about college entrance examination. Many researches exists lots of theories and summaries, but they neglect teaching experiments and innovative ideas. Many of their conclusions are subjective and small part of them study with experiments. Many studies remain studying on the mobile learning system in parts of several schools nearby, or stay in the ideal exploration in theory, or still study foreign theories about it. So, for the college entrance examination reform started in 2017, especially the pilot provinces of Zhejiang and Shanghai, do they still stay in the groping stage about adopting the theory of the classselection system? Has high schools in areas of Zhejiang province formed the new teaching mode with its own characteristics? And what are the pros and cons of this teaching mode?

\section{THE CHARACTERISTICS OF CLASS-SELECTION SYSTEM}

Domestic counterparts on the high school "walking class system" teaching mode of residence before the college entrance examination reform, many of these studies are less heavy, heavy theory, experimental summary, less refined. There are many speculative conclusions, many of which are subjective, rarely by experimental research methods and research. Class teaching research, stay on the ideal go class teaching discussion, stay in the theory class teaching go on foreign take a lot of researches in several schools in some areas of the. So for the comprehensive reform of college entrance examination started in 2017, especially the pilot provinces of Zhejiang and Shanghai, they adopt the class teaching theory is still in the exploratory stage? Go to the senior high school class teaching model, each school below Zhejiang in each region have formed with its own characteristics of the teaching mode? How to implement the pros and cons of class teaching in high school? In the process of classroom teaching, everywhere manifests with students as the center, training student's the basic skills, enable student's physical health and full development, and meet the training requirements of the international society for qualified citizens.

\section{A. The teaching class is not fixed}

The optional class system in senior school breaks the previous fixed class teaching mode. The students gathered together in a class for the same course. Different types of students have opportunities to learn and communicate with each other. It makes students learn about each other more and contact with other students more than before [3] with the end of the course, students need to move from one classroom to another classroom to learn, which greatly promotes the 
students' learning consciousness. Which course will I go to study in the next class? Which classroom will I be in? Through some self - questioning, students will be ready for the next lesson quickly. Relative to fixed classes, students are not willing to leave the classroom, on the surface for more learning time, but it's a quite tired process for the students and affects the efficiency of learning. Optional class let the students relax the brain through a short period. It's more conducive to the next class of learning and will have a positive effect on learning. The optional class teaching model in essence is optimizing classroom teaching mode. It itself has the advantage and attraction of people-oriented, for all students, teach students in accordance of their aptitude and development of all.

\section{B. Enhance the awareness of independent learning}

In the senior school optional class system, students choose subjects according to their own development needs. Students' learning desire is strengthened and students' interest in learning is increased. Combined with their own actual needs, students reasonably arrange the choice of subjects and master of their own learning process. Everyone has their own course timetable. In the condition of past traditional fixed class teaching, students are waiting for the teacher to spread knowledge and psychological preparation is not the same. In the optional class, the majority students are ready for the next class and students' mentality will be better. With the autonomous right of choice, students can choose the suitable subjects according to their own actual situation, greatly improving the initiative of student learning.

\section{From fixed teacher's classroom to fixed classroom teacher}

In the high school optional class system, teachers in a fixed classroom teach knowledge to students. It can let the teacher have enough time to prepare the contents before the next class. From the teaching courseware, teaching forms and other aspects of the full preparation, it is conducive to the full study of students and decreases the waste of time of classroom. Students' academic atmosphere is formed unconsciously. It provides students more experience in person. Students can listen to the advice of professional teachers and parents in order to make more scientific and reasonable development of their own future development of the curriculum. Naturally, take classes in this form in the course of the implementation of the process came into being, not just the class location changes, students will change. In the course of walking, students will be exposed to more different levels of different personality types of students, will inevitably produce more exchanges, therefore also expanded the scope of interpersonal communication.

\section{THE RESEARCH METHODS OF TEACHING MODE FOR THE CLASS-SELECTION SYSTEM}

Mainly through the education research, education experimental study, class observation study. There are many types of educational investigation, questionnaire and interview, survey, questionnaire. Mainly through a large number of firsthand information from the questionnaire and interview, it provides a real and specific and vivid data and information to discuss related research go class teaching. It can also provide the basis on decision-making for the Department of education.
Study on optional class system problems in practice and expose problems, so that we can promote the experimental study on optional class system.

The type of experimental research in education is exploratory experiments and verification experiments. We can analysis of walking class system, teaching in the situation of the new college entrance examination and the new curriculum reform from taking the verification experiment on peer researchers concluded, , For the new curriculum reform, we use the exploratory experiment on optional class system with some experimental education encountered in high school,.

The class observation is an important form of education study. Classroom observation, as a professional activity and a research method of observation, recording, analysis and study of classroom, has important sense to improve the students' learning, promote teachers' development and form school culture. Under the new curriculum reform of high school optional class system, the class observation, is helpful for us to find out optional class system of middle school students learning situation, promote the teacher in the class teaching process improvement and to form the unique features of the school new teaching mode.

Here we point out that the education system of teaching experimental research is an innovation of teaching model research methods for the new college entrance examination class. First, examine, modify, improve and perfect the theory of high school optional class system. The discussion on new college entrance examination combine theoretical research and empirical research to analysis the problems of high school optional class system so that they can give the solution to the optional class system. Second, the reform and development of promoting the teaching practice of senior high school optional class system. On the one hand, it seeks to make the theory specific and apply it to the teaching practice in senior high school. On the other hand, through the education experiment, under the man-made environment, with the guidance of scientific theory, it helps schools and teachers to improve teaching quality and teacher's qualities and deepen the new curriculum reform and the new college entrance examination.

\section{THE NECESSARY CONDITIONS OF THE CLASS-SELECTION SYSTEM TEACHING}

High school optional class system let each student find their interests in learning. After choosing their elective subject, students' learning interest will be improved. The optional class system ensure that the course of students autonomy, accord to the principle of teaching students in a accordance of their aptitude and the active fully mobilize the students' enthusiasm and passion for learning and e arouse the enthusiasm of students' learning desire. In the optional class system, the teachers rethink and improve themselves in the teaching process. High school teacher offer good teaching method and skills for students to form a good environment and atmosphere of learning. Teachers can see students' characteristics and use appropriate methods to guide students and make students always keep a good heart to the world. 


\section{A. Perfect elective system}

Students need the teacher in the classroom under the guidance of selecting suitable courses. Elective courses need professional guidance teachers, must have knowledge of each student. The guidance teacher needs to introduce students to clear all aspects of the course. For the course of learning, can give students time to adapt to, can let the students have a choice. Let the students have a better plan for the future development and choose a suitable course. If during this period the students themselves found that the selected course is not suitable, or too simple or too complex, you can apply, through the teacher in charge, the instructor and the parents agree, you can change the class or retire. In order to make the students more scientific and orderly course, we organized the students "elective" step by step: the first step, the introduction of course information, do a good job in preparing the network. The second step, strengthen the selection of guidance, respect for the personality of students. The third step, printed on the card, to improve the efficiency of elective courses. The fourth step, it is the organization of group selection and validation selection results.

\section{B. Efficient management system.}

In Class-Selection-System teaching during the high school, every teacher is irreplaceable. And in high school the level of teachers' management in class will directly determine the success or failure of the teaching, and high school teachers are responsible for their teaching classes. The teachers create a good learning environment and conditions, promoting students learning effectively, improving the quality and efficiency of teaching. Teachers should be as soon as possible familiar with all the students in class, which to promote the communication between teachers and students, to strengthen the class management, to improve the efficiency of teaching. In the high school Class-Selection-System teaching, each student is also irreplaceable, so teachers need to guide students to learn by themselves. Students mostly understand the situation of students, which can achieve the self-management of students by students to students. The ultimate goal of classroom teaching is not to impart knowledge to students, but to guide students, to give full play to their potential and tap their creative potential to solve this problem. Teaching management is complex system engineering, involving a wide range, the need for various departments and teachers to grasp the common tube, so the regular and occasional class teachers will be held is very necessary. The main topics of the class teacher will is bulletin, research and collaborative solve the problem of the class, teach students in class teaching to every one of the teachers to understand the full range and time to plug the loopholes, coordinate with each other, in order to achieve the best effect of teaching management. Pay attention to the main role of students in learning, promote students' self-education, self-management, self-learning is an important link in the management of class. We have formed a federation of student self-governance in the form of "serving students". It is an important basic level democratic form for students to realize self-education, self-management and self-service. The main responsibilities of the organization is responsible for each class of the normal learning activities such as class, test, experiment of attendance and oversight, guidance class management group, responsible for the class commissary in charge of studies meeting held, go to class to create a good learning environment. After the implementation of class teaching, each teacher has played an irreplaceable role, the level of teacher classroom management will directly determine the effectiveness of classroom teaching and success or failure. Therefore, do a good job in class teaching requirements of all teachers in the first to change the role, enhance the sense of responsibility, establish management first consciousness, so that my class I was responsible. Teachers should be to maximize the creation of good learning environment and conditions, promote students to learn effectively, improve the quality and efficiency of teaching.

\section{Plenty teaching guarantee}

In Class-Selection-System teaching during the high school, schools according to the needs to assign teachers. "Students are the center of the classroom" should be fully reflected in the class; to some degrees students are given the right to choose their own courses. At the same time, the assessment to high school teachers' comprehensive quality will be the higher, so they need to continue to learn and study in order to get progress in teaching, to meet the student's learning needs. High school teachers should not only have the ability to cultivate student's innovative ability, but also to enhance students' academic and research ability. Students can turn their interests to specialty under the guidance of high school teachers, and study some projects to develop good learning habits for the future, setting the foundation for scientific research. For high school teachers, it is also a challenge. They need to improve their scientific research level to cultivate excellent students. In the past, the traditional class teaching system, the whole school student's curriculum arrangement and the subject choice are all stipulated and implemented by the school. In teachers and classroom resources limited circumstances, each semester curriculum making more trouble, not only to consider the classroom quantity, but also the need to avoid every teacher every day the class not with other classes coincide, but also take into account the teacher one day of class number should not be too much, otherwise easily lead to burnout affects the teaching effect. If a teacher of grade is also different, the curriculum will be when we use "after class" teaching, the school each semester only needs to develop two kinds of curriculum: one of the school teachers, curriculum, another is students' personal schedule. All the students in each semester early, just login school online course selection system, required to choose their own course, the last generation of a piece to belong to own personal schedule can be. Teachers of all subjects are only required in accordance with the schedule, every day class in the classroom and time fixed, no longer for the class and hurried running in the classroom, and have sufficient time to the subject do preparation before class. The class-selection system teaching can make that the school curriculum development work become more scientific and concise.

\section{ACKNOWLEDGEMENT}

This research was financially supported by the National Science Foundation of Zhejiang Province (LY12A01010). 


\section{REFERENCES}

[1] Lan Ye. Educational principle. Beijing: People's Education, 2007. (In Chinese)

[2] Zhiwei Deng. The personalized teaching theory. Shanghai China: Shanghai Education, 2002. (In Chinese)

[3] Guodong Hua. Difference teaching theory. Beijing: Education Science, 2001. (In Chinese)
[4] Dajun Zhang. Education psychology. Beijing: People's Education, 2004. (In Chinese)

[5] Tianbao Zhang. The new curriculum and the reform of classroom teaching. Beijing: People's Education, 2003. (In Chinese)

[6] Qiquan Zhong etc. Ordinary high school new curriculum plan introduction. Shanghai: East China Normal University, 2004. (In Chinese) 